\title{
A CASE OF MULTIPLE SYNOSTOSES SYNDROME
}

\author{
Toyoshi Tsuruta, Masaharu Yamazaki, and Tamotsu Yamazaki \\ Department of Orthopaedic Surgery, Mie University School of Medicine, \\ Edobashi, Tsu, Mie 514, Japan
}

\begin{abstract}
Summary A case of multiple synostoses syndrome is reported. The patient was a 20-year-old Japanese female who had bilateral humeroradio-ulnar synostoses, vertebral fusions, calcaneocuboid coalitions, fusions of Lisfranc's joints, symphalangism and, in addition, craniosynostosis. At present, it is not clearly known whether or not the multiple synososes with craniosynostosis and those without craniosynostosis represent different clinical entities. This problem should be elucidated by careful clinical and genetic studies. The importance of whole body examination in such cases is emphasized
\end{abstract}

\section{INTRODUCTION}

In 1972, Maroteaux et al. described seven patients who had symphalangy of the fingers and toes, ankylosis of the elbow joints and deafness under the title "la maladie des synostoses multiples." Since that time, several cases with similar abnormalities have been reported. At present, this disorder is classified as "multiple synostoses (including some forms of symphalangism)" in the category of dysostoses with predominant involvement of the extremities.

The purpose of this paper is to report a case of multiple synostoses syndrome who also had craniosynostosis.

\section{CASE REPORT}

\section{T.N., a 20-year-old Japanese female}

The patient was the third child of a healthy 35-year-old mother and a 35-yearold father. The first male sibling was stillborn, but the second male sibling was healthy. The family history revealed no consanguinity or other congenital anomalies (Fig. 1).

The mother has a bicornic uterus. During the first trimester of the third pregnancy, she was given progesterone injections for the treatment of atypical genital

Received November 9, 1979 


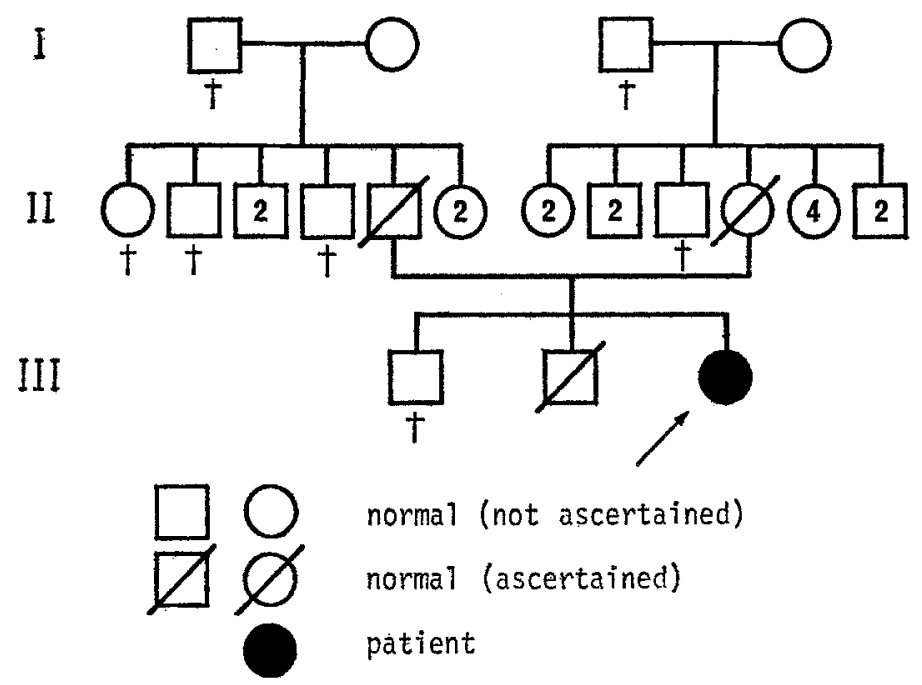

Fig. 1. Pedigree of the family.

bleeding. The patient was born at term by caesarian section because of the weakness of the labour. Her birth weight was $2,900 \mathrm{~g}$. She was noted at birth to have fixed extension-deformity of both elbow joints, and a large head with exophthalmos and hypertelorism. She began to walk without assistance when 18 months old. At the age of 4 years, parasagittal craniectomies were carried out under the diagnosis of Crouzon syndrome, and osteotomy of the right elbow was performed in order to correct the extension-deformity. Since that time, no special treatment for the deformities has been administered.

\section{Clinical findings}

Physical examination revealed a fat female who was $125 \mathrm{~cm}$ in height and 63 $\mathrm{kg}$ in weight. She has unusual facies with exophthalmos. Although formal audiometric examination was not performed, there was no obvious hearing deficit. In the standing position, the spinal column showed marked lordosis not only in the lumbar region, but also in the thoracic region (Fig. 2). The right elbow joint was fixed in a moderately flexed position and the left one in an extended position (Fig.

Fig. 2. External appearance of the patient.

Fig. 3. External appearance of both elbows.

Fig. 4. Antero-posterior roentgenogram of the skull demonstrating a number of digital impres sions.

Fig. 5. Lateral roentgenogram of the skull demonstrating the trace of craniectomy, shallow orbits and hypoplasia of maxillae.

Fig. 6. Antero-posterior roentgenogram of the thoracic spine demonstrating irregular outlines of some vertebrae and failure of segmentation.

Fig. 7. Lateral roentgenogram of the thoracic spine demonstrating lordosis and fusion of some vertebrae. 

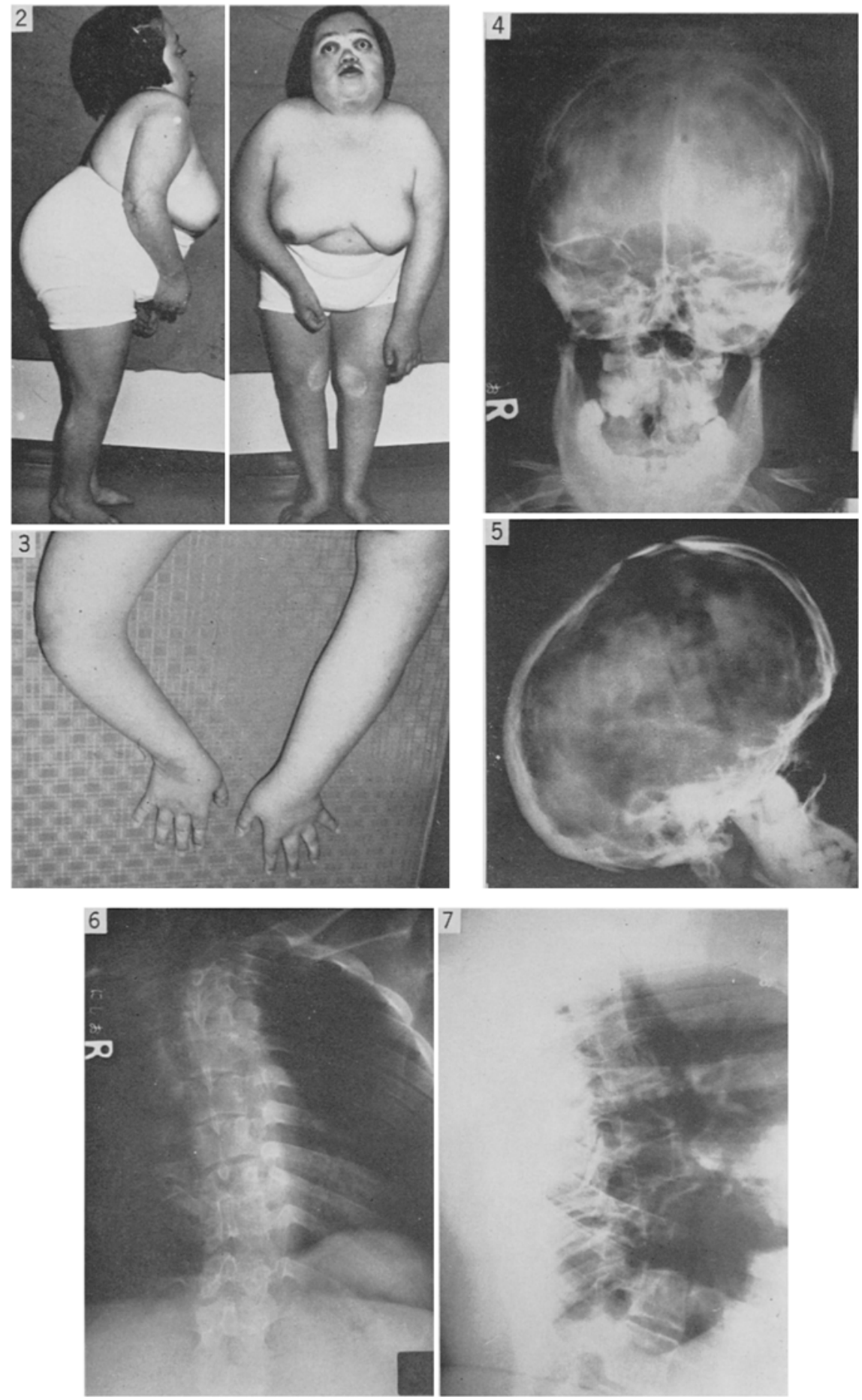

Vol. 25, No. 1, 1980 

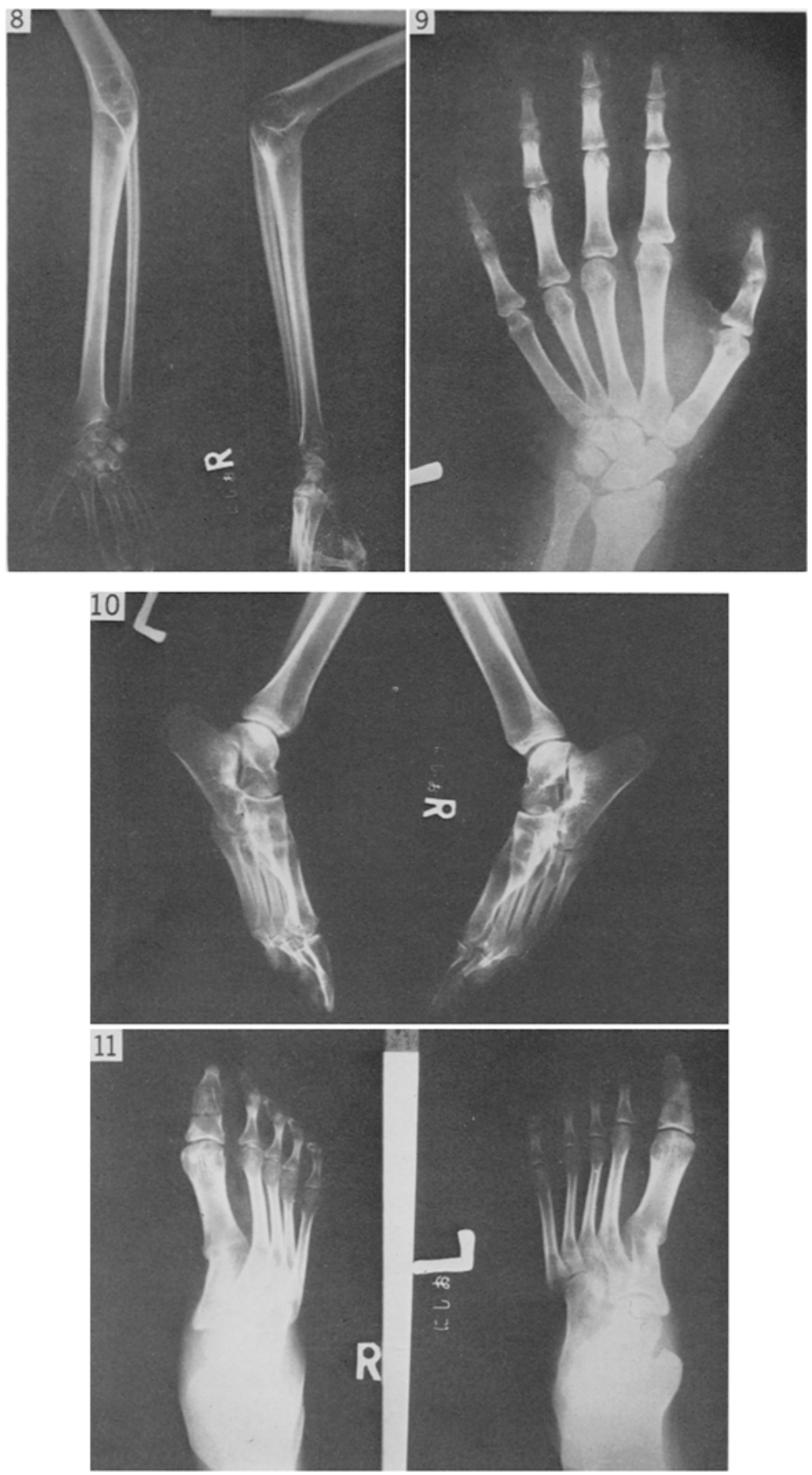

Jpn. I. Human Genet. 
3). Active and passive motion of both elbow joints and pronation and supination of both forearms were completely limited. Although interphalangeal joints of both thumbs were ankylosed, other finger joints showed almost normal range of motion.

\section{Roentgenological findings}

In the skull, a number of digital impressions and traces of craniectomies were noted. The maxillae were hypoplastic with shallow orbits, and the mandible showed a slight foreward protrusion (Figs. 4 and 5).

In the spine, several vertebrae showed irregular outlines and failure of segmentation on the antero-posterior roentgenogram (Fig. 6). A lateral roentgenogram showed lordosis of the thoracic spine and several vertebral fusions (Fig. 7).

In the extremities, both elbow joints showed bony ankylosis of the humerus, radius and ulna (Fig. 8). The interphalangeal joints of the thumbs were fused, and some other finger joints showed narrowing of the joint space (Fig. 9). Although apparent coalition could not be found in the carpal bones, roentgenograms of the feet revealed symmetrical calcaneocuboid coalition and fusion of the bases of the three medial metatarsals to the tarsal bones (Fig. 10), and fusion of the interphalangeal joints of the big toes (Fig. 11).

\section{DISCUSSION}

On the basis of the clinical and roentgenological findings described above, it seems reasonable to classify this patient as one with multiple synostoses syndrome. This syndrome is considered to be inherited as an autosomal dominant character with variable penetrance.

Craniosynostosis associated with multiple synostoses syndrome offers some problems to be discussed. Craniosynostosis can be observed as a feature of some other syndromes including acrocephalosyndactyly, especially Apert syndrome, Carpenter syndrome and Crouzon syndrome. In these syndromes, other than Crouzon syndrome, the correct diagnosis may be possible from associated clinical features such as syndactyly or polysyndactyly. As to the Crouzon syndrome, some authors believe that the pathological changes of this syndrome are confined to the cranial and facial bones, and are never found in other parts of the skeleton. Actually, however, a number of cases of "Crouzon syndrome" with skeletal anomalies in their extremities have been reported in various literatures. For example, Craig

Fig. 8. Roentgenograms of both elbow joints demonstrating bony ankylosis.

Fig. 9. Dorso-palmar roentgenogram of the hand demostrating fusion of the interphalangeal joint of the thumb.

Fig. 10. Lateral roentgenograms of the feet demonstrating calcaneocuboid coalitions and partial fusion of Lisfranc's joint.

Fig. 11. Dorso-plantar roentgenograms of the feet demonstrating fusion of Lisfranc's joints and some interphalangeal joints.

Vol. 25 , No. 1,1980 
and Goldberg (1977) described an 8-year-old girl with "Crouzon syndrome" and bilateral calcaneocuboid coalitions and considered that tarsal fusion might represent an as yet unidentified component of that syndrome. Antley et al. (1975) reported on a girl with craniosynostosis somewhat suggestive of Crouzon syndrome who had multiple synostoses in her extremities. Ventruto et al. (1976) described a syndrome of brachydactyly, symphalangism, synostosis of some carpal and tarsal bones and craniosynostosis in five members of an Italian family, and suggested that their disorders might represent a previously undescribed autosomal dominant trait. Berant et al. (1973) reported a family in which the mother had radioulnar synostosis, one son had craniosynostosis, and each of other three children had craniosynostosis and radioulnar synostosis. They suggested that craniosynostosis and radioulnar synostosis might be transmitted as an autosomal dominant trait with variable expression. In their report, however, presence or absence of synostosis in other parts of the body was not mentioned.

On the other hand, patients with multiple synostoses but without craniosynostosis have also been reported. Inagaki et al. (1961) described a 16-year-old Japanese girl who had symmetrical humero-radio-ulnar synostosis, coalitions of some tarsal and metatarsal bones and symphalangism. Christian et al. (1975) reported a mother and her daughter with metacarpal and metatarsal asymmetry, tarsal and carpal fusions, long bone articular dysplasia and platyspondyly as cases of possible autosomal dominant syndrome. Kassner et al. (1976) described three patients with proximal symphalangism, metacarpophalangeal synostoses, tarsal and carpal fusions and humeroradial synostoses in three generations of a family. Moreover, the authors pointed out the fact that two members of this family were previously reported by Pearlman et al. (1964) as examples of the Nievergelt syndrome. But, because these patients did not have the mesomelic dysplasia that is an integral part of the Nievergelt syndrome, they proposed that the term "Nievergelt-Pearlman syndrome" should be dropped. Nixon et al. (1978) reported a father and his daughter who were similarly affected and used the term "multiple synostoses syndrome."

As cited above, a number of cases reported in the literatures suggest the autosomal dominant inheritance of the multiple synostoses syndrome. Although the patient reported in this paper appeared to be a sporadic case, it would be possible that she might be a product of new dominant mutation. Additional case reports with complete skeletal survey are needed to help clarify the genetic factors in this syndrome. At the present time, it is not clearly known whether or not the multiple synostoses with craniosynostosis and those without craniosynostosis represent different clinical entities. This problem should also be elucidated in the near future by clinical and genetic studies. We wish to emphasize that all the clinicians who encounter patients with craniosynostosis or congenital synostoses in some parts of the body should, without fail, examine the whole body carefully, and, if necessary, perform a complete radiological survey of the skeleton. 


\section{REFERENCES}

Antley, R., and Bixler, D. 1975. Trapezoidocephaly, midfacial hypoplasia and cartilage abnormalities with multiple synostoses and skeletal fractures. Birth Defects: Original Article Series, XI(2), pp. 397-401.

Berant, M., and Berant, N. 1973. Radioulnar synostosis and craniosynostosis in one family. $J$. Pediatr. 83: 88-90.

Christian, J.D., Franken, E.A., Lindeman, J.P., Lindseth, R.E., Reed, T., and Scott, C.I. 1975. A dominant syndrome of metacarpal and metatarsal asymmetry with tarsal and carpal fusion, syndactyly, articular dysplasia and platyspondyly. Clin. Genet. 8: 75-80.

Craig, C.L., and Goldberg, M.L. 1977. Calcaneocuboid coalition in Crouzon syndrome (craniofacial dysostosis). Report of a case and review of literature. J. Bone Jt. Surg. 59-A: 826-827.

Inagaki, Y., Aoki, M., and Muramoto, K. 1961. A case of synostosis humero-radio-ulnaris (in Japanese). Orthopedic Surgery 12: 721-726.

Kassner, E.G., Katz, I., and Qazi, Q.H. 1976. Symphalangism with metacarpophalangeal fusions and elbow abnormalities. Pediat. Radiol. 4: 103-107.

Maroteaux, P., Bouvet, J.P., and Briard, M.L. 1972. La maladie des synostoses multiples. Nouvelle Presse Méd. 1/45: 3041-3047.

Nixon, J.R. 1978. The multiple synostoses syndrome. A plea for simplicity. Clin. Orthop. 135: $48-51$.

Pearlman, H.S., Edkin, R.E., and Warren, R.F. 1964. Familial tarsal and carpal synostosis with radial head subluxation (Nievergelt's syndrom). J. Bone Jt. Surg. 46-A: 585-592.

Ventruto, V., Di Gilolamo, R., Festa, B., Romano, A., Sebastio, G., and Sebastio, L. 1976. Family study of inherited syndrome with multiple congenital deformities: symphalangism, carpal and tarsal fusion, brachydactyly, craniosynostosis, strabismus, hip osteochondritis. J. Med. Genet. 13: $394-398$. 